\title{
Práticas pedagógicas inovadoras: o uso do podcast na perspectiva da sala de aula invertida
}

\author{
Claudia Smaniotto Barin - PPGEPT/UFSM - claudiabarin@ufsm.br \\ Tiago Saidelles - PPGEPT/UFSM - tiago-saidelles@redes.ufsm.br \\ Ricardo Machado Ellensohn - UNIPAMPA/UFSM - \\ ricardoellensohn@unipampa.edu.br
}

Leila Maria Araújo Santos - PPGEPT/UFSM - leilamas@ctism.ufsm.br

\begin{abstract}
Resumo. Este artigo descreve o relato de uma experiência de uso do Podcast como elemento inovador e produtor de conhecimento, numa perspectiva de sala de aula invertida. Metodologicamente o trabalho apoia-se na metodologia da Pesquisa Baseada em Design, tendo como público alvo 50 estudantes matriculados na Disciplina de Química Agronomia. Como instrumentos de coleta de dados foram utilizadas a rede social Facebook, bem como a atividade de estudo proposta na rede e uma enquete, disponibilizada a posteriori. Os resultados obtidos apontam para a flexibilidade $e$ a potencialidade do Podcast no âmbito educacional, possibilitando engajar o estudante no processo de aprendizagem, por meio da produção de conteúdos.
\end{abstract}

Palavras-chave: Sala de aula invertida. Aprendizagem centrada no aluno. Produção de conteúdo digital.

\section{Innovative pedagogical practices: the use of podcast from the flipped classroom perspective}

\begin{abstract}
This article describes the account of an experience using Podcast as an innovative and knowledge-producing element from an inverted classroom perspective. Methodologically the work is supported by the methodology of Design Based Research, having as target audience 50 students enrolled in Agronomy Chemistry Discipline. As data collection instruments were used the social network Facebook, as well as the proposed study activity on the network and a survey, made available a posteriori. The obtained results point to the flexibility and the potentiality of the Podcast in the educational scope, allowing engaging the student in the learning process, through the production of contents.
\end{abstract}

Keywords: Flipped Classroom. Student-centered learning. Production of digital content. 


\title{
1. Introdução
}

$\mathrm{O}$ contexto atual requer dos educadores novas práticas pedagógicas alinhadas às necessidades e demandas decorrentes dos avanços tecnológicos. Essa inovação perpassa por diversos espaços e possibilidades relacionadas ao ambiente escolar, desde a elaboração de materiais didáticos, até o processo avaliativo.

Em consonância com a inovação educacional, as metodologias ativas surgem como uma alternativa para práticas pedagógicas, que estimulem a construção do conhecimento e não simplesmente, a transmissão de informações, muitas vezes desconexas da realidade dos estudantes. A sala de aula invertida (SAI) - Flipped Classroom, é um modelo de metodologia ativa interessante, apoiada na inversão da sala de aula, ou seja, os alunos estudam em casa e aplicam o conhecimento adquirido em situações reais proposta em classe [Pavanelo; Silva, 2017; Pascoal; Souza, 2018].

Para Moran (2015), a SAI é constituída por dois componentes: um que requer a interação humana, situação comum no ambiente escolar, e outro que é desenvolvida, normalmente por meio do uso das tecnologias educacionais, como vídeo aulas, leituras, pesquisas (atividades fora da sala de aula). As atividades extraclasse possuem foco no conteúdo, enquanto as ações em sala de aula, tem o estudante como elemento central.

Dentre as tecnologias educacionais que podem contribuir para a efetivação da sala de aula invertida destaca-se o Podcast. Segundo Jesus (2014), o uso desse recurso no âmbito educacional vem crescendo, principalmente devido a sua flexibilidade.

Para Soares e Barin (2017, p.8), "o Podcast se destaca como um recurso que proporciona aos aprendizes, oportunidades reais de construção de conhecimento, e ao mesmo tempo, condições para estes se tornarem pesquisadores e produtores". Dentro dessa perspectiva, Bottentuit Jr (2007) afirma que o uso do Podcast no contexto educacional pode despertar o interesse dos estudantes pelo aprendizado, bem como flexibilizar o processo de construção do conhecimento, visto que respeita os diferentes ritmos de aprendizagem. Ademais, segundo o autor, o Podcast possibilita ultrapassar os muros da sala de aula.

Outras vantagens apresentadas pelo autor:

\begin{abstract}
Se os alunos forem estimulados a gravar episódios aprendem muito mais, pois terão maior preocupação em preparar um bom texto e disponibilizar um material correto e coerente para os colegas; e). Falar e ouvir constitui uma atividade de aprendizagem muito mais significativa do que o simples ato de ler. Por outro lado, como os trabalhos no podcast são geralmente realizados em grupo e a investigação mostra que a aprendizagem colaborativa tem vantagens sobre a individualizada, temos mais um argumento a favor da utilização desta nova ferramenta em contexto pedagógico [Bottentuit Jr, 2007, p.841]
\end{abstract}

No entanto, como aponta Soares (2017), o uso do Podcast por si só, não modifica o processo de ensino e aprendizagem, assim, ele deve ser planejado como uma ferramenta que, combinada com outras atividades e recursos educacionais, desperta o interesse e flexibiliza o processo de construção de saberes. Dentro dessa perspectiva, o 
presente trabalho visa apresentar e discutir a experiência de uso do Podcast, numa perspectiva de sala de aula invertida.

\section{Metodologia}

O trabalho apoia-se na metodologia da Pesquisa Baseada em Design Educacional, considerada uma metodologia flexível que integra métodos qualitativos e quantitativos de análise. Essa metodologia é comumente realizada em contextos reais, em colaboração entre pesquisador e participantes, através de ciclos iterativos de design e redesign, buscando formas alternativas para resolução de problemas [Wang; Hannafin, 2005].

O público alvo consistiu de 50 estudantes, regularmente matriculados na Disciplina de Química Agronomia. A disciplina ocorre na modalidade presencial, tendo um componente teórico e outro experimental. A mediação pedagógica ocorre para o componente teórico no Ambiente Virtual Moodle e no componente experimental em um grupo fechado da Rede Social Facebook ${ }^{\circledR}$. Os instrumentos de coleta de dados foram a Rede Social Facebook $\mathbb{\circledR}$, os Podcasts postados e a enquete disponibilizada após a atividade.

Antes das aulas presenciais experimentais eram propostas atividades de estudo numa perspectiva de sala de aula invertida, onde os estudantes deviam procurar resolver problemas ou produzir conteúdo, os quais balizam as aulas práticas, que ocorriam a posteriori. Nesse trabalho abordaremos uma dessas atividades - a produção de um Podcast educativo.

A Figura 1 apresenta uma das atividades de estudo propostas, na qual os estudantes deveriam produzir um Podcast, e postar na Rede Social, de forma a compartilhar o conhecimento com seus pares e, compreender o conteúdo, antes deste ser abordado no componente experimental. 
- Administrador - 26 de setembro às $14: 38$

Olá pessoal! Passando para relembrar que semana que vem não haverá aula prática de Química.

Assim, deixo uma atividade que deve ser enviada pela dupla um dia antes da próxima aula prática (ou seja 07,08 e 09 de outubro).

Vamos lá, sei que vocês irão arrasar.

\section{SOLUÇÃO TAMPÃO}

\section{O que é?}

\section{Para que serve?}

Como se aplica à agricultura?

Pesquise sobre as soluções-tampão, e sua importância para prática agricola.

Grave um podcast (áudio) e poste no grupo do Facebook. Comente ao menos um dos podcasts de seus colegas.

O trabalho deverá ser feito em dupla.

Ao iniciar a gravaçẵo do áudio diga o título do mesmo e ao final, os autores do trabalho.

Os áudios podem ser gravados diretamente no celular, ou

usando o programa Audacity (Software livre).

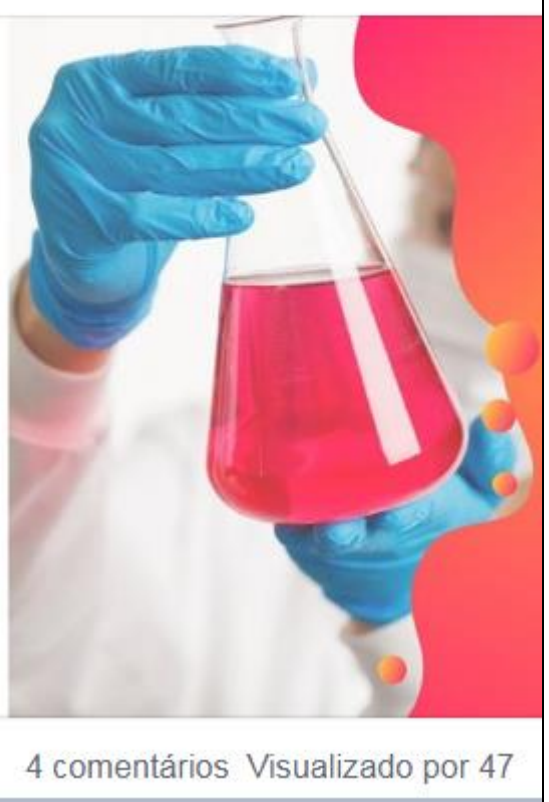

Figure 1. Atividade de estudo proposta

Nesse contexto, os resultados obtidos a partir dessa prática pedagógica são relatados e discutidos a seguir.

\section{Resultados e Discussão}

Logo após a postagem da atividade, vários estudantes visualizaram a proposta e marcaram seus colegas para iniciarem o processo de produção. A atividade despertou o interesse dos estudantes, que se engajaram rapidamente, questionando a professora sobre aplicativos e formas de produção do arquivo de áudio. Como afirma Squizzani(2018, p.4) "o podcast é uma mídia bastante adequada para a divulgação de temas relacionados ao ensino, pois é de fácil acesso e de baixo custo".

Considerando o objetivo educacional, foi flexibilizada a forma de produção do conteúdo, sendo que o mesmo poderia ser gravado nos dispositivos móveis, através de aplicativos específicos, como por exemplo o Podbean e o Google Podcasts, bem como diretamente do gravador de áudio do Smartphone. Alguns estudantes fizeram uso do próprio gravador de áudio do dispositivo móvel para produzir seu conteúdo.

Após a produção dos áudios, os mesmos foram compartilhados no grupo fechado do Facebook®. Essa dinâmica visava possibilitar que todos os integrantes do 
grupo (professores, monitor e estudantes) pudessem ouví-lo. Os podcasts criados foram de vários tipos, desde o formato entrevista até o formato de conteúdo.

Envolver os estudantes em processos de produção de conteúdo requer desses a organização do conhecimento de forma a criar a estutura do material. Esse processo pode contribuir de forma significativa para a produção do conhecimento, visto que o estudante adquire papel de protagonista do processo. A aprendizagem com foco no estudante, é uma premissa da SAI, visto que o estudante assume papel de destaque no processo de construção do saber [Pavanelo; Silva, 2017]. Ao tornar-se ativo, os processos cognitivos estabelecidos pelo estudante (memória de trabalho) são mais eficientes, possibilitando-o estabelecer correlações, criar esquemas mentais, transpor o saber adquirido para outras situações e assim, atingir ou potencializar a memória de longo prazo, como afirma Mayer (1998).

A figura 2 apresenta um exemplo de como o material foi postado por uma das duplas. As identidades foram suprimidas, de forma a garantir $\mathrm{o}$ anonimato dos participantes.

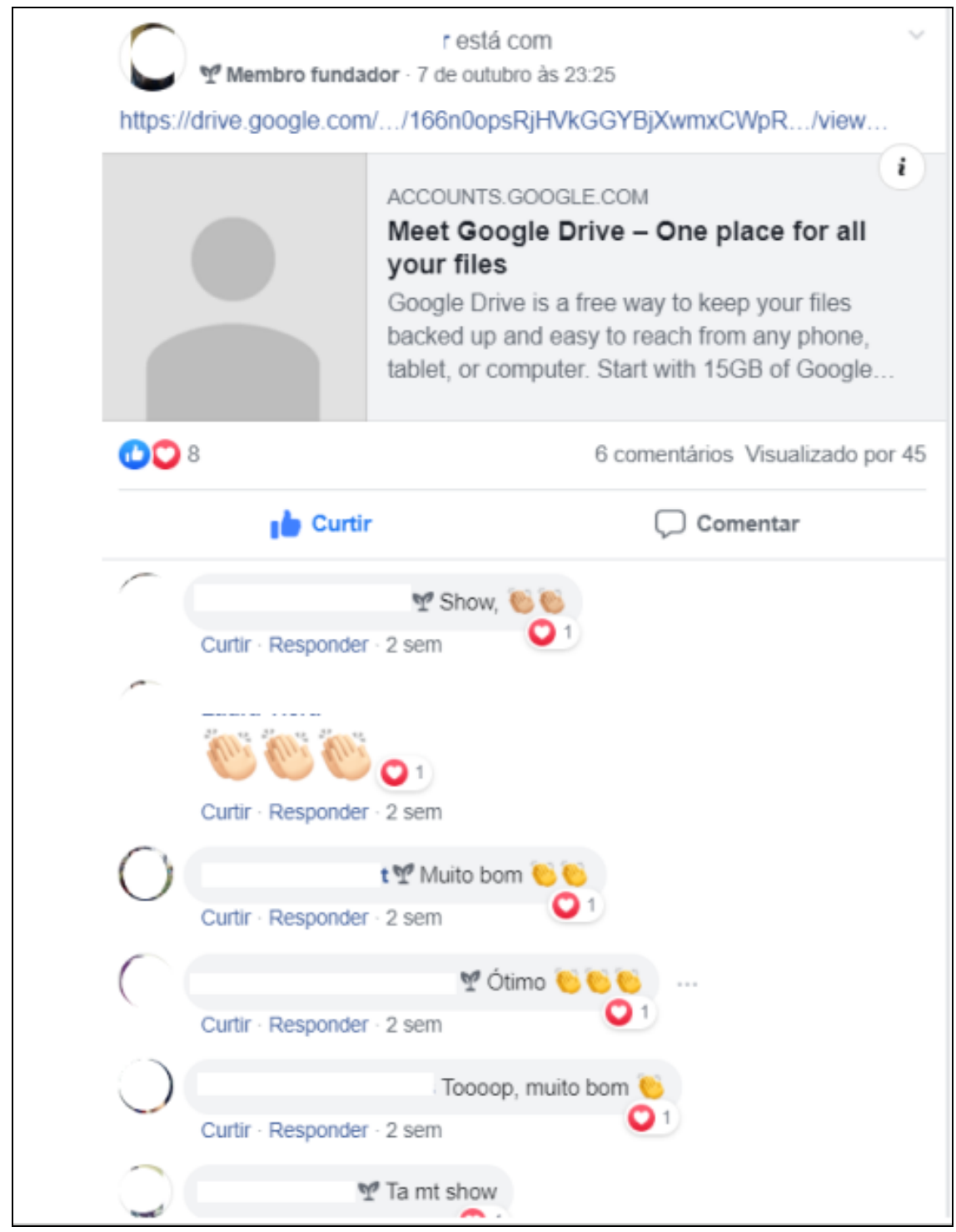

Figure 2. Exemplo de post com o conteúdo solicitado 
Pode-se observar que a postagem foi visualizada pela maior parte do grupo, sendo que muitos estudantes demonstram apoio aos colegas por meio de palavras de incentivo. Essa participação estimula os demais membros a também executarem um trabalho interessante. Para acessar ao áudio, bastava solicitar a autorização aos autores, que prontamente disponibilizavam o acesso.

Analisando os comentários feitos pelos pares (colegas), pode-se perceber que a atividade teve excelente aceitação, rompendo com a primeira barreira do processo de ensinar e aprender, ou seja, os alunos tornaram-se mais receptivos ao conteúdo. Além dos comentários explicitados na Figura 2, os estudantes foram questionados, durante a aula experintal que ocorreu posteriormente. Nessa conversa informal, pode-se verificar que os mesmos sentiram-se satisfeitos e valorizados com a atividade. Isso pode estar relacionado ao fato que grandes empresas de comunicação passaram a dar ênfase a essa forma de compartilhamento de conteúdos, além disso possibilitar aos mesmos serem protagonistas do processo, lhes confere confiança para atividades futuras.

Além disso, como afirmam Santos e Morano (2017), as ferramentas disponíveis nas redes sociais fomentam a aprendizagem colaborativa, uma vez que aceitam o compartilhamento de diferentes mídias e formatos de conteúdo. Ademais, o fato dos estudantes estarem familiarizados com elas, potencializam sua forma de participação, não requerendo treinamentos prévios.

No intuito de avaliar a atividade proposta, lançou-se na rede social uma enquete, para que os estudantes pudessem compartilhar com os demais, os sentimentos e como visualizavam a produção de Podcast. Os resultados podem ser visualizados na Figura 3.

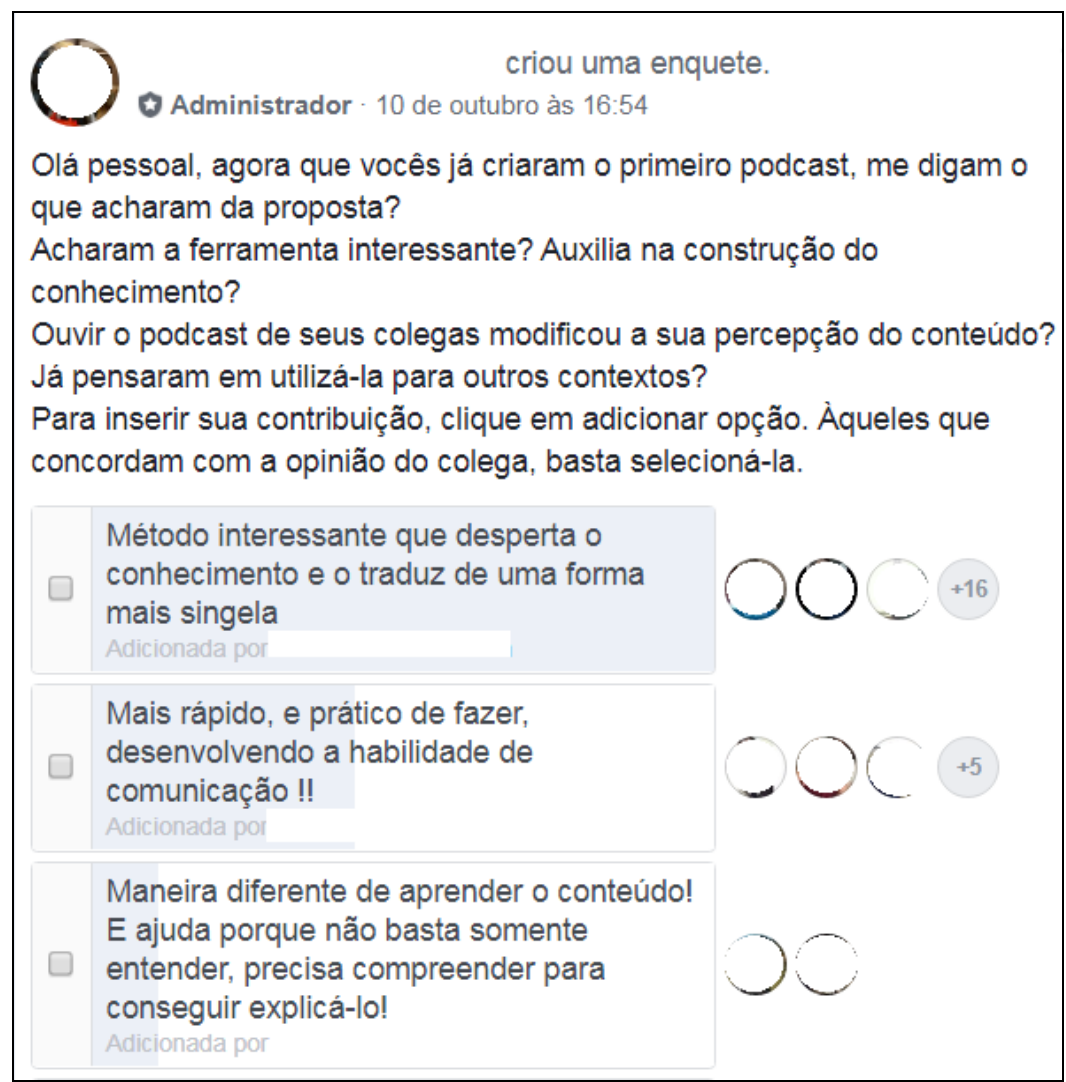

Figure 3. Resultado da enquete realizada no grupo fechado da Rede Social 
Como pode-se observar, na figura 3, dezenove (19) estudantes concordam que a atividade Podcast lhes despertou interesse pelo conteúdo, ou seja, é uma forma interessante de chamar a atenção dos alunos para os conteúdos abordados em sala de aula. Essa opção pode estar relacionada ainda, ao fato do professor requerer que estes realizassem a associação entre o conceito químico e a aplicação desse conceito na futura área de atuação profissional dos estudantes. Ou seja, os mesmos percebem a importância, devido a relevância da temática para sua formação.

Essa perspectiva alinha-se ao pensamento de Machado (2005), que afirma que a contextualização é uma estratégia essencial para a construção de significações na medida em que incorpora relações tacitamente percebidas. Para a autora, a incorporação de relações vivenciadas e valorizadas no contexto em que se originam na trama de relações em que a realidade é tecida enriquecem a aprendizagem.

A segunda opção apontada pelos estudantes, quanto a praticidade de produção do conteúdo esta fortemente ligada a forma como estes se relacionam com as tecnologias. Por terem nascido num universo tecnológico e, terem crescido cercados por aparatos tecnológicos, já desenvolveram ao longo de sua existência, a fluência necessária para não apenas fazer uso das ferramentas tecnológicas, mas sim produzir conteúdos digitais a partir dessas.

Ademais, essa constatação está alinhada ao que afirma Bottentuit Jr (2007), que o processo de gravar-se e escutar a si próprio e aos pares propicia uma aprendizagem mais significativa que meramente ler. Ou seja, o processo de produção de conteúdo, requer do estudante um maior envolvimento e reflexão acerca da temática abordada, aumentando o envolvimento desse no processo de construção do conhecimento e assim, tornando a aprendizagem mais significativa.

Com base na terceira opção apontada pelos estudantes podemos verificar que a opinião dos estudantes corrobora a afirmativa de Bottentuit Jr (2007), descrita anteriormente, pois quando os estudantes afirmam que "Maneira diferente de aprender o conteúdo! E ajuda porque não basta somente entender, precisa compreender para explicá-lo", percebe-se que propor-lhes atividades como está requer deles um engajamento maior, de forma a disponinilizar aos colegas um material coerente e correto.

Bottentuit (2007) aponta ainda que nesse universo globalizado em que se vive atualmente, o podcast surge como uma alternativa prática e de baixo custo para acessar a informação, além de ser uma metodologia motivadora. Para o autor proporcionar ao aluno sair do mero padrão de consumidor de informação para produtor de informação, pode contribuir de forma significativa para a aprendizagem, engajando os sujeitos aprendentes no processo e valorizando seu potencial comunicativo.

\section{Considerações finais}

Com base na experiência relatada é possível afirmar que a inovação proposta promoveu o interesse dos estudantes pela atividade, modificando a práxis e a relação entre o estudantes e professores. Essa mudança possibilita romper com alguns paradigmas educacionais, propiciando o diálogo e a humanização da prática educativa. 
As ferramentas de autoria de conteúdo modificam o papel do estudante no processo de construção do conhecimento, na medida que requer desses uma participação efetiva e a compreensão da temática, para um melhor desempenho autoral. Nesse sentido, modificam-se os papeis dos atores da aprendizagem e o professor deixa de ser o protagonista do processo, para tornar-se um mediador da construção do conhecimento.

A proposição de atividades na perspectiva da SAI ampliam o espaço da sala de aula e proporcionam aos estudantes o desenvolvimento de habilidades, como a produção de conteúdo, a comunicação, entre outras, promovendo a autonomia e a criticidade. Desse modo, entendemos que a SAI é uma alternativa interessante para antecipar conteúdos em disciplinas experimentais, pois proporcionam aos estudantes compreender os conceitos envolvidos no decorrer dos experimentos, e assim, promover uma aprendizagem mais significativa.

Os dados retornantes da pesquisa nos permitem afirmar que atividades como esta, engajam os estudantes, tornando-os parceiros da construção coletiva de saberes. Torná-los protagonistas, os incentiva a seguir em frente e promove o interesse pela aprendizagem. Outro fator que contribui significativamente para promoção do engajamento dos estudantes, é propor atividades de estudo ou de pesquisa, que estejam correlacionadas com sua área de formação, pois conteúdos desconexos do dia a dia ou da realidade da área de formação tornam-se pouco atraentes e comumente depreciados pelos estudantes.

Por fim, para que práticas inovadoras como essa obtenham sucesso, é necessário, no entanto, que o professor esteja aberto a mudanças, buscando diversificar suas aulas e propor atividades centradas nos estudantes, e não meramente no conteúdo.

\section{Referências}

Bottentuit Junior, J. e Coutinho, C. P.. Podcast em Educação: um contributo para o estado da arte. In A. Barca, M. Peralbo, A. Porto, B. D. Silva, e L. Almeida (Eds.), Actas do IX Congresso Internacional Galego Português de Psicopedagogia (pp. 837-846). Setembro, Universidade da Coruña, 2007.

Jesus, W. Podcast e Educação: um Estudo de Caso. 2014. Dissertação (Mestrado em educação) Universidade Estadual Paulista Júlio de Mesquita Filho, Rio Claro, SP, 2014.

Machado, N. J. Interdisciplinaridade e contextualização. In: Ministério da Educação, Instituto Nacional de Estudos e Pesquisas Educacionais Anísio Teixeira. Exame Nacional do Ensino Médio (ENEM): fundamentação teórico-metodológica. Brasília: MEC; INEP, 2005. p. 41-53.

Mayer, R.E.; Moreno, R. A split-attention effect in multimedia learning: Evidence for dual processing systems in working memory. Journal of Educational Psychology, v. 90, p. 312-320, 1998. 
Moran, K.; Milson, A.. The Flipped Classroom in Counselor Education. Counselor Education and Supervision, 2015. Disponível em: http://onlinelibrary.wiley.com/doi/10.1002/ceas.2015.54.issue-1/issuetoc. Acesso em: 15 out. 2019.

Paschoal, L.N.; Souza, S.R.S.. Planejamento e Aplicação de Flipped Classroom para o Ensino de Teste de Software. Renote, v.16, n.2, p. 1-10, 2018.

Pavanelo, E.; Lima, R.. Sala de Aula Invertida: a análise de uma experiência na disciplina de Cálculo I. Bolema, Rio Claro, v. 31, n. 58, p. 739-759, 2017.

Disponível em: http://www.scielo.br/scielo.php?script=sci_arttext\&pid=S0103636X2017000200739\&lng=en\&nrm=iso. Acesso em: 27 Out. 2019.

Santos, E.G.dos; Morano, R.S.. Adoção e uso do Facebook na educação: perspectivas para a comunicação, colaboração e compartilhamento de informações e dados no ambiente universitário. Revista Gestão \& Tecnologias, v. 17, n. 3, p.63-87, 2017.

Soares, A.B.; Barin, C.S. Podcast: potencialidades e desafios na práxis educativa. Revista Tecnologias na Educação, v.14, art.33, p.1-10, 2016. Disponível em: http://tecedu.pro.br/wp-content/uploads/2016/07/Art33-vol14-jul2016-Podcast-

Potencialidades-e-desafios-na-pr\%C3\%A1xis-educativa.pdf. Acesso em 20 out. 2019.

Soares, A. B. O uso pedagógico do Podcast na Educação Profissional e Tecnológica. Dissertação de Mestrado. Universidade Federal de Santa Maria - UFSM. Colégio Técnico Industrial - Programa de Pós-Graduação em Educação Profissional e Tecnológica. Santa Maria -RS, 2017. Disponível em: https://repositorio.ufsm.br/handle/1/13870, Acesso em 28 out 2019.

Squizzani, F.. O uso do podcast como mediador do ensino e da informação no Centro de Tecnologia da Universidade Federal de Santa Maria. Trabalho de Conclusão de Curso - Especialização TICs 2018. Disponível em: https://repositorio.ufsm.br/handle/1/15533. Acesso em: 24 out. 2019.

Wang, F. Hannafin, M. J.. Design-based research and technology-enhanced learning environments. Educational technology research and development, v. 53, n. 4, p. 523, 2005. 